\title{
Characteristics of Dutch and Swiss primary care COPD patients - baseline data of the ICE COLD ERIC study
}

This article was published in the following Dove Press journal:

Clinical Epidemiology

I| October 20 II

Number of times this article has been viewed

Lara Siebeling'
Milo A Puhan

Patrick Muggensturm ${ }^{4}$

Marco Zoller ${ }^{5}$

Gerben ter Riet ${ }^{1}$

'Department of General Practice, Academic Medical Center, University of Amsterdam, The Netherlands;

${ }^{2}$ Department of Epidemiology, Bloomberg School of Public Health, Johns Hopkins University, Baltimore, MD, USA; ${ }^{3}$ Horten Center for Patientoriented Research, University of Zurich, ${ }^{4}$ Department of Respiratory Medicine, University Hospital of Zurich, Zurich, Switzerland; ${ }^{5}$ Department of General Practice, University of Zurich, Zurich, Switzerland
Correspondence: Lara Siebeling Academic Medical Center, University of Amsterdam, Department of Clinical Methods and Public Health, Room J2-I I4, Meibergdreef 9,1105 AZ Nederland $\mathrm{Tel}+3$ I 205668382

Email l.siebeling@amc.uva.nl
Introduction: International Collaborative Effort on Chronic Obstructive Lung Disease: Exacerbation Risk Index Cohorts (ICE COLD ERIC) is a prospective cohort study with chronic obstructive pulmonary disease (COPD) patients from Switzerland and The Netherlands designed to develop and validate practical COPD risk indices that predict the clinical course of COPD patients in primary care. This paper describes the characteristics of the cohorts at baseline.

Material and methods: Standardized assessments included lung function, patient history, self-administered questionnaires, exercise capacity, and a venous blood sample for analysis of biomarkers and genetics.

Results: A total of 260 Dutch and 151 Swiss patients were included. Median age was 66 years, $57 \%$ were male, $38 \%$ were current smokers, $55 \%$ were former smokers, and $76 \%$ had at least one and $40 \%$ had two or more comorbidities with cardiovascular disease being the most prevalent one. The use of any pulmonary and cardiovascular drugs was $84 \%$ and $66 \%$, respectively. Although lung function results (median forced expiratory volume in 1 second $\left[\mathrm{FEV}_{1}\right]$ was $59 \%$ of predicted) were similar across the two cohorts, Swiss patients reported better COPD-specific health-related quality of life (Chronic Respiratory Questionnaire) and had higher exercise capacity.

Discussion: COPD patients in the ICE COLD ERIC study represent a wide range of disease severities and the prevalence of multimorbidity is high. The rich variation in these primary care cohorts offers good opportunities to learn more about the clinical course of COPD.

Keywords: COPD, exacerbation, health-related quality of life, prediction, prognosis

\section{Introduction}

Most patients with chronic obstructive pulmonary disease (COPD) are managed by general practitioners (GP). GPs face the challenge of providing effective health care for patients with a highly heterogeneous disease to reduce the great impact of COPD on patients' lives. An important part of the management includes an evaluation of disease severity and its implications for the choice of treatments. Interestingly, GPs do not base the evaluation of COPD patients on lung function only but consider other prognostically important markers such as history of exacerbations or dyspnea. ${ }^{1,2}$ Such practice is supported by evidence that shows that lung function incompletely reflects patients' health state and is, in fact, associated only weakly with prognosis. ${ }^{2-6}$ There is increasing agreement among experts that characterizing patients should be based on combinations of prognostically important characteristics such as frequency of exacerbations, exercise capacity, and dyspnea that better reflect the multifaceted nature of COPD than a single parameter. ${ }^{7}$ 
An attractive approach for combining patient characteristics are scores such as the BODE (body mass index, obstruction, dyspnea, and exercise capacity), ADO (age, dyspnea, and obstruction) or DOSE (dyspnea, obstruction, smoking status, and exacerbation frequency) indices. ${ }^{1,3,8}$ Such scores can be used to assess the risk for premature mortality or exacerbations and may guide therapeutic management. Unfortunately, there seems to be low awareness for these indices in primary care, ${ }^{9}$ which may be due to the unavailability of some components such as the 6-minute walk distance or the lack of validation in primary care cohorts. The ADO and DOSE indices overcome some of these limitations by including only parameters easily available in primary care. ${ }^{1,8}$ However, GPs may also be interested in the prediction of the clinical course of their patients in terms of measures of symptoms and health-related quality of life. Therefore, disease severity indices for COPD patients should be developed or at least validated in primary care populations because they may reflect a COPD population that is different from many COPD cohorts that are mainly recruited in secondary and tertiary care centers. The International Collaborative Effort on Chronic Obstructive Lung Disease: Exacerbation Risk Index Cohorts (ICE COLD ERIC) study was designed to develop and validate such practical COPD severity indices in primary care patients with Global Initiative for Chronic Obstructive Lung Disease (GOLD) stages II-IV. ${ }^{10}$ This paper describes baseline characteristics and provides a detailed characterization of the ICE COLD ERIC cohorts.

\section{Methods and design}

ICE COLD ERIC is an international study in which two prospective cohort studies with primary care COPD patients (GOLD stages II-IV) from Switzerland and The Netherlands are linked. All included patients have provided written informed consent. The study has been approved of by all local ethics committees and is registered on ClinicalTrials. gov (NCT00706602).

\section{Population}

Included patients are $\geq 40$ years of age with COPD in GOLD stages II-IV who were able to complete the baseline assessment and had been free of exacerbation for at least 4 weeks. Exclusion criteria were a life expectancy of $\leq 12$ months, dementia, psychosis or other psychiatric morbidity that would invalidate assessment of patientreported parameters, and inability to complete the baseline assessment due to language difficulties. Patients were included between April 2008 and April 2009.
A single protocol for both countries was designed for the baseline assessment and follow-up assessments. To ensure comparability, we developed and pilot tested case report forms and instructions for testing. Investigators meet twice a year and have frequent telephone and email contact to ensure that the assessments remain similar in both countries. More details on the study protocol were reported elsewhere. ${ }^{10}$

\section{Study design and methods}

The baseline assessment ${ }^{10}$ consisted of lung function measurement (forced expiratory volume in 1 second $\left[\mathrm{FEV}_{1}\right]$, forced vital capacity [FVC], and inspiratory reserve volume [IRV]) after bronchodilation with two puffs of $100 \mu \mathrm{g}$ salbutamol through a spacer, a detailed patient history with general information (date of birth, sex, living situation, occupation, and education) and COPD-specific information (year of diagnosis, smoking history, current smoking, exposure to smoke at home, exacerbations, chronic cough, and phlegm), detailed registration of comorbidities, and use of drugs and any nondrug treatments for COPD and other diseases (self-reported). It also included measurement of BMI (as calculated by height/weight ${ }^{2}$ ). All patients completed several questionnaires. To assess dyspnea, they completed the Medical Research Council ${ }^{11}$ (MRC) dyspnea scale with a score of zero to four where zero is "no or little dyspnea associated with heavy physical activity" and four is "too breathless to leave the house or breathless when (un) dressing." For COPD-specific health-related quality of life, the Chronic Respiratory Questionnaire (CRQ) was used. ${ }^{12-14}$ The CRQ provides scores in four different domains (dyspnea, fatigue, emotional, and mastery) each on a scale of one to seven, where one is the worst score indicating very poor health-related quality of life and seven the best. Patients scored their health on the Feeling Thermometer, ${ }^{15-17}$ a scale of zero (very bad) to 100 (very good) and they answered three questions for measuring self-efficacy, the patient's belief in his or her skills to manage the illness. A short COPD-specific instrument was used to measure the patient's self-efficacy. It contained three questions for coping with COPD, dyspnea, and the use of pulmonary drugs, respectively, on a fivepoint scale from one (not confident) to five (very confident). Finally, the hospital anxiety and depression scale ${ }^{18,19}$ (HADS) was used to provide scores for depression and anxiety. Scores above eight indicate that a depression and/or anxiety disorder is likely to be present. Two tests were performed to measure exercise capacity, the sit-to-stand test and the handgrip strength test. During the sit-to-stand test patients hold their hands on their hips and they complete the sitting and standing 
positions on a chair without arm rests for 1 minute as correctly and as fully as possible without using the arms for support. ${ }^{20}$ The handgrip test is used to assess grip strength of both hands with the Jamar ${ }^{\circledR}$ Hydraulic Hand Dynamometer (JA Preston Corporation, Jackson, MI). ${ }^{21}$ A blood sample was taken from each patient to measure creatinine, bilirubin, alanine-aminotransferase, total cholesterol, high-density lipoprotein cholesterol, low-density lipoprotein cholesterol, triglycerides, C-reactive protein, carboxyhemoglobin, and leukocytes. A differential blood count was performed and DNA was extracted and stored at $-80^{\circ} \mathrm{C}$. Finally, for every patient, ADO and DOSE indices were calculated. ${ }^{1,8}$ The ADO index estimates the 3 -year mortality risk and the DOSE index estimates health status. Of note, the ability of the ADO and DOSE indices to predict mortality, exacerbations, and health status in these populations will be reported when follow-up assessments are completed.

\section{Statistical analysis}

Summary statistics were calculated for all variables. Percentages and absolute numbers are used to describe dichotomous and categorical variables. Median, fifth percentile, and 95th percentile are used to describe continuous variables. The fifth percentile means that only $5 \%$ of the observed values is lower than that value and the 95th percentile means that $95 \%$ is lower than that value (and only 5\% higher). Data were analyzed using Stata software (v 10.1; StataCorp, College Station, TX).

\section{Results}

Table 1 summarizes general and COPD-specific patient characteristics. Male/female ratio was 50/50 for the Dutch and 68/32 for the Swiss cohort. The median age was 66 years in the Dutch and 67 years in the Swiss cohort. Half of the patients in both cohorts had a diagnosis of COPD for less than 5 years and $19 \%$ of the Swiss and $9 \%$ of the Dutch patients had this diagnosis for less than 1 year. The median number of pack years was 37 for the Dutch and 45 for the Swiss cohort. The percentage of smokers vs former smokers was $40 \%$ vs $53 \%$ for the Dutch cohort and 35\% vs 58\% for the Swiss cohort. Four percent of the Dutch cohort reported they had never smoked in their life vs $6 \%$ of the Swiss cohort. Around $33 \%$ of patients had one or more exacerbations in the previous year. The median MRC score was 2.5 for the Dutch and one for the Swiss cohort; 39\% of the Dutch cohort had the maximum (worst) MRC score vs $0 \%$ of the Swiss cohort. Median, fifth, and 95th percentiles of MRC scores for each of the three GOLD categories were also calculated.
Figure 1 shows the frequencies of comorbidities and of their simultaneous presence. These Venn diagrams show comorbidities and multimorbidities for the Dutch cohort, the Swiss cohort, and the total cohort. The diagrams are next to each other, the sharing of the cells is similar, and the percentages in the cells represent the (overlap of) comorbidity, which makes it easy to compare the cohorts with each other. Group A (black) represents cardiovascular disease consisting of coronary artery disease, chronic heart failure, and cerebrovascular disease. Group B (red) represents type 1 and type 2 diabetes mellitus. Group C (blue) represents musculoskeletal disease, mainly osteoarthritis and rheumatoid arthritis. Group D (green) represents other comorbidities such as asthma, malignancies, and infectious disease.

As shown in Table 2, 88\% of the Dutch cohort used pulmonary drugs vs $76 \%$ of the Swiss cohort with the highest percentages for inhaled corticosteroids and long-acting beta-agonists. Around 14\% used antidiabetic drugs, usually oral antidiabetics, and $66 \%$ had at least one cardiovascular drug, usually anticlotting. Around $40 \%$ in both cohorts had nondrug interventions, mainly physical exercise. Around $8 \%$ in the Dutch cohort and $10 \%$ in the Swiss cohort had pulmonary rehabilitation.

In all CRQ domains Swiss patients had higher scores than Dutch patients (Table 3). HADS anxiety scores were quite similar whereas the HADS depression scores indicated more symptoms of depression in the Dutch cohort compared to the Swiss cohort. As expected, the CRQ dyspnea domain patients in higher GOLD categories had more dyspnea. For the other CRQ domains, Feeling Thermometer and HADS, the differences between patients in different GOLD categories were small.

In both exercise capacity tests the Swiss cohort showed higher exercise capacity than the Dutch cohort (Table 4). For the sit-to-stand test, differences were small between GOLD categories and no difference between GOLD categories for the hand grip test results was observed. The median score on the ADO index was five for the Dutch cohort and three for the Swiss, meaning that the Dutch had a higher risk of 3-year mortality than the Swiss, 16.3\% (fifth to 95th percentile: $7.9 \%-26.5 \%$ ) vs $11.5 \%$ (fifth to 95 th percentile: $7.9 \%-19.3 \%$ ). The median score on the DOSE-index was two for the Dutch cohort and one for the Swiss cohort, suggesting that Swiss patients had a better health status (as measured by the CCQ total score) than the Dutch.

The median values of $\mathrm{FEV}_{1}$ percentage $\left(\mathrm{FEV}_{1} \%\right)$ of predicted were $58 \%$ and $59 \%$ and $\mathrm{FEV}_{1} / \mathrm{FVC}$ ratio were 0.52 and 0.57 for the Dutch and the Swiss cohort, respectively 
Table I Patient characteristics of 260 Dutch and I5I Swiss chronic obstructive pulmonary disease patients (total cohort $\mathrm{N}=4 \mathrm{I}$ I) enrolled in the International Collaborative Effort on Chronic Obstructive Lung Disease: Exacerbation Risk Index Cohorts prospective cohort study

\begin{tabular}{|c|c|c|c|}
\hline & $\begin{array}{l}\text { Dutch cohort } \\
\mathrm{n},(\%)\end{array}$ & $\begin{array}{l}\text { Swiss cohort } \\
\mathrm{n},(\%)\end{array}$ & $\begin{array}{l}\text { Total cohort } \\
\mathrm{n},(\%)\end{array}$ \\
\hline \multicolumn{4}{|l|}{ Sex } \\
\hline Male & $130(50.0)$ & $103(68.2)$ & $233(56.7)$ \\
\hline Female & $130(50.0)$ & $48(31.8)$ & $178(43.3)$ \\
\hline \multicolumn{4}{|l|}{ Age } \\
\hline p5, p50, p95 & $51,66,83$ & $52,67,81$ & $51,66,82$ \\
\hline \multicolumn{4}{|l|}{ BMI } \\
\hline p5, p50, p95 & $18.8,25.5,35.8$ & $19.8,25.2,35.1$ & $19.5,25.4,35.1$ \\
\hline \multicolumn{4}{|l|}{ Living situation } \\
\hline Alone & $103(39.6)$ & $46(30.5)$ & $149(36.3)$ \\
\hline With partner & $117(45.0)$ & $95(62.9)$ & $212(51.6)$ \\
\hline With children & $12(4.6)$ & $3(2.0)$ & $15(3.6)$ \\
\hline With partner and children & $28(10.8)$ & $5(3.3)$ & $33(8.0)$ \\
\hline Unknown & $0(0.0)$ & $2(1.3)$ & $2(0.5)$ \\
\hline \multicolumn{4}{|l|}{ Profession } \\
\hline Working & $53(20.4)$ & $36(23.8)$ & $89(21.7)$ \\
\hline House wife & $21(8.1)$ & I (0.7) & $22(5.4)$ \\
\hline Retired & $132(50.8)$ & $106(70.2)$ & $238(57.9)$ \\
\hline Disabled & $53(20.4)$ & $8(5.3)$ & $61(14.8)$ \\
\hline Unemployed & I $(0.4)$ & $0(0.0)$ & $\mathrm{I}(0.2)$ \\
\hline \multicolumn{4}{|l|}{ Highest education } \\
\hline Primary school & $57(21.9)$ & $21(13.9)$ & $78(19.0)$ \\
\hline Secondary school & II 5 (44.2) & $105(69.5)$ & $220(53.5)$ \\
\hline Intermediate vocational & $53(20.4)$ & $15(9.9)$ & $68(16.5)$ \\
\hline Higher vocational/university & $34(13.1)$ & $6(4.0)$ & $40(9.7)$ \\
\hline Unknown & I $(0.4)$ & $4(2.6)$ & $5(1.2)$ \\
\hline \multicolumn{4}{|l|}{ Diagnosis of COPD since } \\
\hline$<$ I year & $23(8.8)$ & $29(19.2)$ & $52(12.6)$ \\
\hline $\mathrm{I}-5$ years & $102(39.2)$ & $45(29.8)$ & $147(35.8)$ \\
\hline $5-10$ years & $48(18.5)$ & 27 (I7.9) & $75(18.2)$ \\
\hline$>10$ years & $65(25.0)$ & $42(27.8)$ & $107(26.0)$ \\
\hline Unknown & $22(8.5)$ & $8(5.3)$ & $30(7.3)$ \\
\hline \multicolumn{4}{|l|}{ Pack years } \\
\hline p5, p50, p95 & I, 37, 82 & $0,45,110$ & I, 40, 90 \\
\hline \multicolumn{4}{|l|}{ Smoking habits } \\
\hline Nonsmoker & $10(3.9)$ & $9(6.0)$ & $19(4.6)$ \\
\hline Former smoker & $137(52.7)$ & $87(57.6)$ & $224(54.5)$ \\
\hline Current smoker & $104(40.0)$ & $53(35.1)$ & $157(38.2)$ \\
\hline \multicolumn{4}{|l|}{ Cigarettes per day } \\
\hline p5, p50, p95 & $3,15,40$ & $3,20,50$ & $3,15,40$ \\
\hline Passive smoker & II (4.2) & $28(18.5)$ & $39(9.5)$ \\
\hline Cigar smoker & $8(3.1)$ & $4(2.7)$ & $12(2.9)$ \\
\hline Pipe smoker & $4(1.5)$ & $6(4.0)$ & $10(2.4)$ \\
\hline \multicolumn{4}{|l|}{ Exacerbations treated at home } \\
\hline 0 & |7| (65.8) & $102(67.5)$ & $273(66.4)$ \\
\hline $\mathrm{I}-2$ & $75(28.8)$ & 47 (3I.I) & $122(29.7)$ \\
\hline$>2$ & $14(5.4)$ & $\mathrm{I}(0.7)$ & I5 (3.6) \\
\hline Unknown & $0(0.0)$ & I (0.7) & $\mathrm{I}(0.2)$ \\
\hline \multicolumn{4}{|l|}{ Exacerbations treated in hospital } \\
\hline 0 & $248(95.4)$ & 137 (90.7) & $385(93.7)$ \\
\hline $\mathrm{I}-2$ & II (4.2) & $12(7.9)$ & $23(5.6)$ \\
\hline$>2$ & I $(0.4)$ & $\mathrm{I}(0.7)$ & $2(0.5)$ \\
\hline Unknown & $\mathrm{I}(0.0)$ & $\mathrm{I}(0.7)$ & $\mathrm{I}(0.2)$ \\
\hline
\end{tabular}


Table I (Continued)

\begin{tabular}{|c|c|c|c|}
\hline & $\begin{array}{l}\text { Dutch cohort } \\
\mathrm{n},(\%)\end{array}$ & $\begin{array}{l}\text { Swiss cohort } \\
\mathrm{n},(\%)\end{array}$ & $\begin{array}{l}\text { Total cohort } \\
\mathrm{n},(\%)\end{array}$ \\
\hline \multicolumn{4}{|l|}{ MRC score } \\
\hline p5, p50, p95 & $0,2.5,4$ & $0,1,3$ & $0,1,4$ \\
\hline GOLD II & $0,1,4$ & $0,1,2$ & $0,1,4$ \\
\hline GOLD III & I, 4,4 & $0,1,3$ & I, 2,4 \\
\hline GOLD IV & $\mathrm{I}, 4,4$ & I, 2, 3 & $\mathrm{I}, 3,4$ \\
\hline 0 & $37(14.2)$ & $34(22.5)$ & 71 (I7.3) \\
\hline 1 & 77 (29.6) & 78 (5।.7) & 155 (37.7) \\
\hline 2 & $16(6.2)$ & $25(16.6)$ & $4 \mathrm{I}(10.0)$ \\
\hline 3 & $28(10.8)$ & $14(9.3)$ & $42(10.2)$ \\
\hline 4 & $102(39.2)$ & $0(0.0)$ & $102(24.8)$ \\
\hline \multicolumn{4}{|l|}{ Chronic cough } \\
\hline Yes & $122(46.9)$ & $79(52.3)$ & 201 (48.9) \\
\hline No & I $38(53.1)$ & $72(47.7)$ & $210(5 \mathrm{I} .1)$ \\
\hline \multicolumn{4}{|l|}{ Chronic phlegm } \\
\hline Yes & $120(46.2)$ & $79(52.3)$ & $199(48.4)$ \\
\hline No & $139(53.5)$ & $70(46.4)$ & $209(50.9)$ \\
\hline Unknown & I (0.4) & $2(1.3)$ & $3(0.7)$ \\
\hline
\end{tabular}

Notes: MRC score is divided into five categories: $0=$ breathless with strenuous exercise, $1=$ breathless when hurrying or walking up a slight hill, $2=$ walks slower than other people of the same age because of breathlessness or has to stop for breath when walking at own pace, $3=$ has to stop for breath after walking 100 yards or after a few minutes, 4 = too breathless to leave the house or breathless while (un)dressing. Numbers in GOLD stage II, III, and IV are I74, 64, and 22 for Dutch, 95, 40, and I6 for Swiss, and 269, 104, and 38 for total cohort.

Abbreviations: BMI, body mass index; COPD, chronic obstructive pulmonary disease; GOLD, Global Initiative for Chronic Obstructive Lung Disease; MRC, medical research council; $\mathrm{p} 5$, fifth percentile, $\mathrm{p} 50$, median, $\mathrm{p} 95,95$ th percentile.

(Table 5). The percentage of A-quality (best) for lung function measurement was $62 \%$ for the Dutch and $38 \%$ for the Swiss cohort. The GOLD classification was as follows: in the Dutch cohort $67 \%$ was classified as GOLD stage II, $25 \%$ as GOLD stage III, and $9 \%$ as GOLD stage IV. In the Swiss cohort $63 \%$ was classified as GOLD stage II, $27 \%$ as GOLD stage III, and $11 \%$ as GOLD stage IV. Laboratory results are shown in Table 6.

\section{Discussion}

The analysis of these cohorts indicates that the impact of COPD was quite different in the Dutch and the Swiss cohort although lung function and the prevalence of comorbidity and multimorbidity were quite similar. Swiss patients reported higher scores on all CRQ domains than Dutch patients and for all domains these differences were 0.5 or higher (minimal important difference $=0.5),{ }^{14}$ indicating that the Swiss
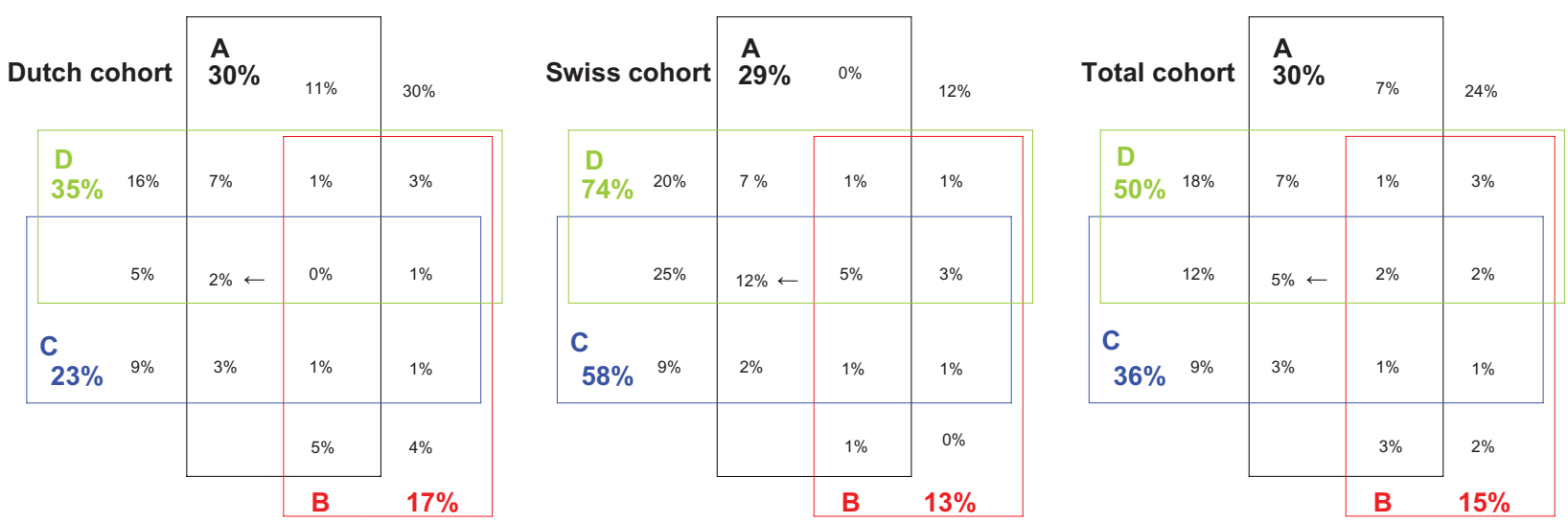

Figure I Comorbidities in Venn diagrams of 260 Dutch and I5I Swiss chronic obstructive pulmonary disease patients (total cohort $\mathrm{N}=4 \mathrm{II}$ ) enrolled in the International Collaborative Effort on Chronic Obstructive Lung Disease: Exacerbation Risk Index Cohorts prospective cohort study. The A box represents cardiovascular disease, B represents diabetes mellitus, $\mathbf{C}$ represents musculoskeletal disease and $\mathbf{D}$ represents other comorbidity. The different boxes with percentages show the overlap of comorbidity. For example, the three cells with arrows show the percentages that fall in group A, C, and D meaning the patient has cardiovascular disease AND musculoskeletal disease AND other comorbidity, but NOT diabetes mellitus. The sharing of the cells is identical in all three subdiagrams to facilitate the comparison of percentages. For example, the cells with the arrows can be easily compared: $2 \%$ in the Dutch cohort versus $12 \%$ in the Swiss cohort versus $5 \%$ in the total cohort. 
Table 2 Drug and nondrug interventions of 260 Dutch and I5I Swiss chronic obstructive pulmonary disease patients (total cohort $\mathrm{N}=4 \mathrm{I}$ I) enrolled in the International Collaborative Effort on Chronic Obstructive Lung Disease: Exacerbation Risk Index Cohorts prospective cohort study

\begin{tabular}{|c|c|c|c|}
\hline & $\begin{array}{l}\text { Dutch cohort } \\
\text { n, (\%) }\end{array}$ & $\begin{array}{l}\text { Swiss cohort } \\
\mathrm{n},(\%)\end{array}$ & $\begin{array}{l}\text { Total cohort } \\
\mathrm{n},(\%)\end{array}$ \\
\hline No drugs at all & $6(2.3)$ & $6(4.0)$ & $12(2.9)$ \\
\hline Pulmonary drugs & $229(88.1)$ & $115(76.2)$ & $344(83.7)$ \\
\hline Ipratropium & $41(17.9)$ & $12(10.4)$ & $53(15.4)$ \\
\hline Local steroids & $164(7 \mid .6)$ & $74(64.3)$ & $238(69.2)$ \\
\hline Long-acting beta-agonists & $169(73.8)$ & $76(66.1)$ & $245(7 I .2)$ \\
\hline Short acting beta-agonists & $80(34.9)$ & $39(33.9)$ & $119(34.6)$ \\
\hline Tiotropium & III (48.5) & $45(39.1)$ & $156(45.3)$ \\
\hline Systemic steroids & II (4.8) & $10(8.7)$ & $21(6.1)$ \\
\hline Parasympaticolytics & $2(0.9)$ & $\mathrm{I}(0.9)$ & $3(0.9)$ \\
\hline Cardiovascular drugs & $172(66.2)$ & $101(66.9)$ & $273(66.4)$ \\
\hline ACE inhibitors & $79(45.9)$ & $37(36.6)$ & $116(42.5)$ \\
\hline Anticlotting & $93(54.1)$ & $65(64.4)$ & $158(57.9)$ \\
\hline Angiotensin-2-receptor inhibitors & $19(11.0)$ & $23(22.8)$ & $42(15.4)$ \\
\hline Beta-antagonists & $57(33.1)$ & $37(36.6)$ & $94(34.4)$ \\
\hline Calcium-antagonists & $34(19.8)$ & $19(18.8)$ & $53(19.4)$ \\
\hline Diuretics & $77(44.8)$ & $48(47.5)$ & $125(45.8)$ \\
\hline Statins & $86(50.0)$ & $34(33.7)$ & $120(44.0)$ \\
\hline Antidiabetic drugs & $38(14.6)$ & $21(13.9)$ & $59(14.4)$ \\
\hline Oral antidiabetics & $25(65.8)$ & II (52.4) & $36(61.0)$ \\
\hline Insulin & $13(34.2)$ & $9(42.9)$ & $22(37.3)$ \\
\hline Analgesia & $38(14.6)$ & $30(19.9)$ & $68(16.6)$ \\
\hline NSAIDs & $14(36.8)$ & II (36.7) & $25(36.8)$ \\
\hline Other & $21(55.3)$ & 14 (46.7) & $35(51.5)$ \\
\hline Psychiatric drugs & $59(22.7)$ & $30(19.9)$ & $89(21.7)$ \\
\hline Antidepressives & $25(42.4)$ & $17(56.7)$ & $42(47.2)$ \\
\hline Anxiolytics/sedative/sleep & $42(7 \mid .2)$ & $15(50.0)$ & $57(64.0)$ \\
\hline Other drugs & $165(63.5)$ & $73(48.3)$ & $238(57.9)$ \\
\hline Nondrug therapies & $100(38.5)$ & $60(39.7)$ & $160(38.9)$ \\
\hline Long-term oxygen treatment & $7(7.0)$ & $5(8.3)$ & $12(7.5)$ \\
\hline Oxygen during exertion & $3(3.0)$ & I (I.7) & $4(2.5)$ \\
\hline Fitness training at home & $15(15.0)$ & $37(61.7)$ & $52(32.5)$ \\
\hline Fitness training in a program & $37(37.0)$ & $23(38.3)$ & $60(37.5)$ \\
\hline Lung volume reduction surgery & $0(0.0)$ & $2(3.3)$ & $2(1.3)$ \\
\hline Pulmonary rehabilitation in the last year & $\mathrm{I}(\mathrm{I} .0)$ & $6(10.0)$ & $7(4.4)$ \\
\hline Pulmonary rehabilitation $>$ I year ago & $7(7.0)$ & $0(0.0)$ & $7(4.4)$ \\
\hline Devices & $62(23.8)$ & $2(3.3)$ & $64(40.0)$ \\
\hline Other & $4(4.0)$ & $7(11.7)$ & II (6.9) \\
\hline
\end{tabular}

Abbreviations: ACE, angiotensin-converting enzyme; NSAIDs, nonsteroidal antiinflammatory drugs.

patients reported better COPD-specific health-related quality of life. On classifying patients according to GOLD category, these differences became even larger. This is also reflected in MRC scores where Dutch patients reported more dyspnea than Swiss patients. In both exercise tests, the Swiss patients showed higher exercise capacity than the Dutch patients. And, the Swiss cohort had a lower 3-year risk of mortality than the Dutch cohort, $11.5 \%$ vs $16.3 \%$.

Approximately $50 \%$ of all patients received their COPD diagnosis less than 5 years ago. Of these, 9\% of the Dutch patients and $19 \%$ of the Swiss had their COPD diagnosis for less than 1 year and were probably diagnosed as a result of their participation in this study. The fact that more Swiss patients were diagnosed within this study may be explained by differences in the identification and recruitment process between Switzerland and The Netherlands. ${ }^{10}$ In Switzerland, GPs known to have an active interest in research activities were involved and, through them, more GPs potentially willing to participate were identified (snowball approach). Participating GPs identified potentially eligible patients through electronic or paper-based patient charts. For electronic patient charts GPs searched with the key terms "COPD," "chronic bronchitis," "emphysema," "asthma," and a combination of "smoking," " $\geq 40$ years of age," and "male" to identify patients with COPD. Paper-based patient charts were screened by hand. Potentially eligible patients were informed about the study and 
Table 3 Patient-reported outcomes of 260 Dutch and I 5 I Swiss chronic obstructive pulmonary disease patients (total cohort N=4I I) enrolled in the International Collaborative Effort on Chronic Obstructive Lung Disease: Exacerbation Risk Index Cohorts prospective cohort study

\begin{tabular}{|c|c|c|c|c|}
\hline & & Dutch cohort & Swiss cohort & Total cohort \\
\hline \multicolumn{5}{|l|}{$\overline{\text { CRQ }}$} \\
\hline Dyspnea & $p 5, p 50, p 95$ & $2.0,4.5,7.0$ & $2.8,5.0,7.0$ & $2.2,4.8,7.0$ \\
\hline GOLD II & & $2.2,5.2,7.0$ & $3.2,5.5,7.0$ & $2.5,5.3,7.0$ \\
\hline GOLD III & & $2.0,3.7,6.8$ & $3.0,4.4,6.7$ & $2.2,4.0,6.8$ \\
\hline GOLD IV & & I.0, 3.I, 7.0 & $2.2,4.4,6.4$ & $1.0,3.2,7.0$ \\
\hline Fatigue & $p 5, p 50, p 95$ & I.8, 4.0, 6.5 & $2.5,5.3,6.5$ & $2.0,4.5,6.5$ \\
\hline GOLD II & & I.8, $4.3,6.5$ & $2.5,5.3,6.5$ & $2.0,4.5,6.5$ \\
\hline GOLD III & & $1.5,4.0,6.5$ & $2.4,4.8,6.0$ & $2.0,4.3,6.0$ \\
\hline GOLD IV & & I.5, 3.8, 5.8 & $2.5,5.4,6.5$ & $1.5,4.0,6.3$ \\
\hline Emotional & p5, p50, p95 & $2.7,5.1,6.9$ & $3.0,5.6,6.7$ & $2.7,5.4,6.7$ \\
\hline GOLD II & & $2.7,5.1,6.7$ & $2.9,5.6,6.6$ & $2.7,5.4,6.7$ \\
\hline GOLD III & & $3.1,5.3,6.9$ & $3.5,5.5,6.5$ & $3.3,5.4,6.9$ \\
\hline GOLD IV & & $2.7,5.1,6.9$ & $2.6,5.8,7.0$ & $2.6,5.5,6.9$ \\
\hline Mastery & $p 5, p 50, p 95$ & $3.3,5.5,7.0$ & $3.5,6.0,7.0$ & $3.3,5.8,7.0$ \\
\hline GOLD II & & $3.0,5.8,7.0$ & $3.5,6.0,7.0$ & $3.3,5.8,7.0$ \\
\hline GOLD III & & $3.8,5.5,7.0$ & $3.3,5.6,6.9$ & $3.8,5.5,7.0$ \\
\hline GOLD IV & & $3.3,5.5,6.8$ & $2.8,6.1,7.0$ & $3.0,5.8,7.0$ \\
\hline \multicolumn{5}{|l|}{ HADS } \\
\hline Depression & p5, p50, p95 & $1,5,12$ & I, 4, 10 & I, 5, II \\
\hline GOLD II & & $1,5,11$ & $0,4,10$ & $0,5,11$ \\
\hline GOLD III & & $1,5,12$ & I, 4, 10 & I, 4, II \\
\hline GOLD IV & & $2,6,12$ & I, 4, II & $1,6,12$ \\
\hline Scores above 8 & n (\%) & $58(22.5)$ & $13(8.7)$ & $71(17.4)$ \\
\hline Anxiety & $p 5, p 50, p 95$ & $0,4,13$ & $0,3,12$ & $0,4,13$ \\
\hline GOLD II & & $0,5,14$ & $0,3,12$ & $0,4,13$ \\
\hline GOLD III & & $0,4,12$ & $1,3,9$ & $0,3,10$ \\
\hline GOLD IV & & $0,5,13$ & $0,2,15$ & $0,5,14$ \\
\hline Scores above 8 & n (\%) & $53(20.5)$ & $13(8.8)$ & $66(16.3)$ \\
\hline \multicolumn{5}{|l|}{ Self efficacy } \\
\hline Illness & $p 5, p 50, p 95$ & $2,4,5$ & $2,4,5$ & $2,4,5$ \\
\hline GOLD II & & $2,4,5$ & $3,4,5$ & $3,4,5$ \\
\hline GOLD III & & $2,4,5$ & I, 4,5 & $2,4,5$ \\
\hline GOLD IV & & $2,4,5$ & I, 5,5 & $2,4,5$ \\
\hline Dyspnea & $p 5, p 50, p 95$ & I, 4,5 & $2,4,5$ & I, 4,5 \\
\hline GOLD II & & I, 4,5 & $2,4,5$ & $2,4,5$ \\
\hline GOLD III & & $2,4,5$ & I, 4,5 & $2,4,5$ \\
\hline GOLD IV & & I, 3, 5 & $2,4,5$ & I, 3, 5 \\
\hline Medication & p5, p50, p95 & $2,5,5$ & I, 5, 5 & I, 5,5 \\
\hline GOLD II & & $2,5,5$ & I, 4,5 & I, 5,5 \\
\hline GOLD III & & $4,5,5$ & I, 5,5 & $2,5,5$ \\
\hline GOLD IV & & $2,5,5$ & I, 5,5 & $2,5,5$ \\
\hline Feeling thermometer & p5, p50, p95 & $44,70,93$ & $40,75,95$ & $43,70,95$ \\
\hline GOLD II & & $45,70,95$ & $50,75,95$ & $45,70,95$ \\
\hline GOLD III & & $47,68,80$ & $40,65,85$ & $47,65,85$ \\
\hline GOLD IV & & $40,60,70$ & $4,63,90$ & $7,60,88$ \\
\hline
\end{tabular}

Notes: CRQ on a scale of one (worst) to seven (best). HADS score $>8$ means anxiety/depression likely. Self efficacy questions on a scale of one (worst) to five (best). Feeling thermometer on a scale of zero (very bad health) to 100 (very good health). Numbers in GOLD stage II, III, and IV are I74, 64, and 22 for Dutch, 95 , 40, and I6 for Swiss, and 269, 104, and 38 for total cohort.

Abbreviations: CRQ, Chronic Respiratory Questionnaire; GOLD, Global Initiative for Chronic Obstructive Lung Disease; HADS, hospital anxiety and depression scale; p5, fifth percentile; $p 50$, median; $p 95,95$ th percentile.

invited by telephone for eligibility testing. In The Netherlands, COPD patients were identified from primary health care centers registered in the GP research network of the Department of General Practice of the University of Amsterdam in Almere and Amsterdam. These patients received study information and an invitation letter from their GP. Patients who were not interested in participating or who did not wish to receive a phone call returned a reply card indicating as much. All patients who did not respond via the reply card were invited by telephone for eligibility testing. 
Table 4 Exercise capacity and age, dyspnea, and obstruction index among 260 Dutch and I5I Swiss chronic obstructive pulmonary disease patients (total cohort $\mathrm{N}=4 \mathrm{II}$ ) enrolled in the International Collaborative Effort on Chronic Obstructive Lung Disease: Exacerbation Risk Index Cohorts prospective cohort study

\begin{tabular}{|c|c|c|c|c|}
\hline & & Dutch cohort & Swiss cohort & Total cohort \\
\hline Sit-to-stand test ( $\mathrm{x} /$ minute) & p5, p50, p95 & $0,14,24$ & $\mathrm{II}, 22,40$ & $0,17,35$ \\
\hline GOLD II & & $0,15,25$ & $12,23,40$ & $0,18,35$ \\
\hline GOLD III & & $0,15,23$ & $0,20,42$ & $0,17,39$ \\
\hline GOLD IV & & $0,10,17$ & $13,18,30$ & $0,13,26$ \\
\hline \multicolumn{5}{|l|}{ Hand grip test } \\
\hline Right hand $(\mathrm{kg})$ & p5, p50, p95 & $16,30,52$ & $20,40,58$ & $18,32,56$ \\
\hline GOLD II & & $15,30,54$ & $18,40,58$ & $17,32,56$ \\
\hline GOLD III & & $18,32,49$ & $21,40,66$ & $18,34,56$ \\
\hline GOLD IV & & $16,30,50$ & $20,4 I, 54$ & $16,36,53$ \\
\hline Left hand $(\mathrm{kg})$ & $p 5, p 50, p 95$ & $12,28,50$ & $20,36,54$ & $14,32,52$ \\
\hline GOLD II & & $12,28,50$ & $20,36,56$ & $14,32,52$ \\
\hline GOLD III & & $14,30,50$ & $18,35,54$ & $16,32,53$ \\
\hline GOLD IV & & $14,27,48$ & $16,37,50$ & $14,29,50$ \\
\hline ADO index & p5, p50, p95 & I, 5, 8 & $1,3,6$ & $\mathrm{I}, 4,7$ \\
\hline DOSE index & $p 5, p 50, p 95$ & $0,2,6$ & $0,1,4$ & $0,1,5$ \\
\hline
\end{tabular}

Notes: ADO index is an estimation of 3-year risk of mortality. A score of five indicates a 3-year risk of mortality of $16.3 \%$, score of 3 indicates a 3 -year risk of mortality of $11.5 \%$, and score of four indicates a 3 -year risk of mortality of $13.7 \%$. DOSE index is an estimation of health status as measured by the CCQ total score. Numbers in GOLD stage II, III, and IV are 174, 64, and 22 for Dutch, 95, 40, and 16 for Swiss, and 269, 104, and 38 for total cohort.

Abbreviations: ADO, age, dyspnea and obstruction; DOSE, dyspnea, obstruction, smoking status, and exacerbation frequency; GOLD, Global Initiative for Chronic Obstructive Lung Disease; p5, fifth percentile; p50, median; p95, 95th percentile.

In terms of the lung function measurement that was performed at study entry, the quality was better in The Netherlands than in Switzerland despite identical devices and a single protocol. It looks as if the number of measurement repetitions was lower in Switzerland thereby lowering the probability that three or more measurements were of high enough quality for an A or B rating to occur.
Site investigators in Switzerland generally stopped repeating the measurements when a diagnosis of COPD was confirmed whereas in The Netherlands the investigators aimed for quality grades A or B by having more repeated measurements to obtain a more reliable measurement. Potential differences in measurement error are currently being investigated by analyzing the exact measurement variability between the

Table 5 Lung function among 260 Dutch and I 5 I Swiss chronic obstructive pulmonary disease patients (total cohort $\mathrm{N}=4 \mathrm{I}$ I) enrolled in the International Collaborative Effort on Chronic Obstructive Lung Disease: Exacerbation Risk Index Cohorts prospective cohort study

\begin{tabular}{|c|c|c|c|c|}
\hline & & Dutch cohort & Swiss cohort & Total cohort \\
\hline $\mathrm{FEV}_{1}(\mathrm{I})$ & p5, p50, p95 & $0.64,1.44,2.56$ & $0.63,1.50,2.47$ & $0.63,1.45,2.56$ \\
\hline $\mathrm{FEV}_{1}, \%$ of predicted & $p 5, p 50, p 95$ & $26,58,77$ & $24,59,79$ & $25,59,78$ \\
\hline FVC (I) & $p 5, p 50, p 95$ & $1.66,2.84,4.55$ & $\mathrm{I} .43,2.84,4.42$ & I.56, $2.84,4.48$ \\
\hline FVC, \% of predicted & p5, p50, p95 & $57,90,118$ & $53,84,117$ & $55,88,118$ \\
\hline $\mathrm{FEV}_{1} / \mathrm{FVC}$ & p5, p50, p95 & $0.29,0.52,0.67$ & $0.31,0.57,0.70$ & $0.29,0.53,0.68$ \\
\hline Inspiratory capacity & p5, p50, p95 & $0.95,2.13,3.68$ & $1.32,2.39,3.63$ & I.I3, 2.23, 3.63 \\
\hline Quality of measurement & A & $162(62.3)$ & $58(38.4)$ & $220(53.5)$ \\
\hline \multirow[t]{4}{*}{$n(\%)$} & B & $64(24.6)$ & $22(14.6)$ & $86(20.9)$ \\
\hline & C & $34(13.1)$ & $36(23.8)$ & $70(17.0)$ \\
\hline & $\mathrm{D}$ & $0(0.0)$ & $34(22.5)$ & $34(8.3)$ \\
\hline & Less than $D$ & $0(0.0)$ & I $(0.7)$ & $\mathrm{I}(0.2)$ \\
\hline GOLD II $(50 \leq$ FEV\% < 80) & & $174(66.9)$ & $95(62.9)$ & $269(65.5)$ \\
\hline \multicolumn{5}{|l|}{ n (\%) } \\
\hline GOLD III $(30 \leq$ FEV\% < 50) & & $64(24.6)$ & $40(26.5)$ & $104(25.3)$ \\
\hline \multicolumn{5}{|l|}{ n (\%) } \\
\hline GOLD IV $\left(\mathrm{FEV}_{1} \%\right.$ < 30) & & $22(8.5)$ & $16(10.6)$ & $38(9.3)$ \\
\hline$n(\%)$ & & & & \\
\hline
\end{tabular}

Abbreviations: $\mathrm{FEV}_{1}$, forced expiratory volume in I second; FVC, forced vital capacity; GOLD, Global Initiative for Chronic Obstructive Lung Disease; p5, fifth percentile; p50, median; $\mathrm{p} 95,95$ th percentile. 
Table 6 Laboratory results among 260 Dutch and I5I Swiss chronic obstructive pulmonary disease patients (total cohort $\mathrm{N}=4 \mathrm{II}$ ) enrolled in the International Collaborative Effort on Chronic Obstructive Lung Disease: Exacerbation Risk Index Cohorts prospective cohort study

\begin{tabular}{|c|c|c|c|c|}
\hline & & Dutch cohort & Swiss cohort & $\overline{\text { Total cohort }}$ \\
\hline Creatinine $(\mu \mathrm{mol} / \mathrm{L})$ & p5, p50, p95 & $48,72,126$ & $63,88,142$ & $50,77,132$ \\
\hline Bilirubin $(\mu \mathrm{mol} / \mathrm{L})$ & $p 5, p 50, p 95$ & $4,8,15$ & $4,8,21$ & $4,8,16$ \\
\hline ALAT (U/L) & p5, p50, p95 & II, 2I, 56 & $12,24,52$ & $12,22,52$ \\
\hline Total cholesterol $(\mathrm{mmol} / \mathrm{L})$ & $p 5, p 50, p 95$ & $3.4,5.3,7.5$ & $3.9,5.8,7.9$ & $3.5,5.5,7.7$ \\
\hline HDL cholesterol (mmol/L) & $p 5, p 50, p 95$ & $0.9,1.5,2.3$ & $0.9,1.5,2.4$ & $0.9,1.5,2.3$ \\
\hline LDL cholesterol (mmol/L) & $p 5, p 50, p 95$ & $1.5,3.1,5.0$ & $1.3,3.3,5.3$ & $1.5,3.2,5.1$ \\
\hline Triglycerides (mmol/L) & $p 5, p 50, p 95$ & $0.6,1.3,3.2$ & $0.7,1.7,4.2$ & $0.6,1.4,3.8$ \\
\hline CRP (mg/L) & p5, p50, p95 & I.0, 3.7, 22.6 & $0.4,2.6,21.7$ & $0.8,3.3,22.2$ \\
\hline $\mathrm{COHb}(\%)$ & p5, p50, p95 & $2.1,3.5,9.1$ & $0.0,1.6,6.2$ & $0.0,2.9,8.6$ \\
\hline Leukocytes (I0E9/L) & $p 5, p 50, p 95$ & $5.1,7.7,12.6$ & $5.0,8.1,12.7$ & $5.1,7.8,12.6$ \\
\hline
\end{tabular}

Notes: Reference values: creatinine male 75-II0, female 65-95; bilirubin < 17; ALAT < 45; total cholesterol male 3.9-6.5, female 3.7-6.5; HDL cholesterol > I.I; LDL cholesterol $<4.5$; triglycerides $0.5-2$; CRP $<5$; COHb nonsmokers $<2 \%$; smokers $<5 \%$; toxic $>15 \%$; leukocytes $4-10.5$.

Abbreviations: ALAT, alanine aminotransferase; CRP, C-reactive protein; COHb, carboxyhemoglobin; HDL, high density lipoprotein; LDL, low density lipoprotein; p5, fifth percentile; $\mathrm{p} 50$, median; $\mathrm{p} 95,95$ th percentile.

countries using intraclass correlations instead of $\mathrm{ABCD}$ ratings.

With regard to representativeness, some basic characteristics (sex, age, pack years, $\mathrm{FEV}_{1} \%$ of predicted, and GOLD classification) of the ICE COLD ERIC cohort have been compared with two other COPD cohorts from the literature (Evaluation of COPD Longitudinally to Identify Predictive Surrogate Endpoints [ECLIPSE] and Investigating New Standards for Prophylaxis In Reducing Exacerbations [INSPIRE]). ${ }^{22,23}$ No differences were seen in age and pack years. In both the ECLIPSE and INSPIRE cohort, the percentage of males was larger $(65 \%$ and $80 \%$, respectively), the $\mathrm{FEV}_{1} \%$ of predicted was lower ( $48 \%$ and $39 \%$, respectively) and the prevalence of GOLD stage III ( $42 \%$ and $82 \%$, respectively) and GOLD stage IV (14\% and $15 \%$, respectively) was higher. Overall, the ECLIPSE and INSPIRE study included more severe COPD patients than the ICE COLD ERIC study, which can be explained by differences in setting and inclusion criteria. ${ }^{22,23}$ The ICE COLD ERIC cohort is a representative cohort for COPD patients in primary care and may be used for purposes of worldwide collaboration on primary care data on COPD. ${ }^{24}$

One strength of the ICE COLD ERIC study is that it is an international prospective study with two cohorts from different countries linked by a single study protocol. Another strength of the study is that these cohorts were recruited in primary care and that the data collection is elaborate, especially with regard to comorbidity and drug use. Although the majority of COPD patients are managed in primary care, many previous cohorts were recruited in hospital settings or COPD clinics, which may reflect a COPD population with different characteristics. Also, comorbidities are often not properly reported in cohort studies. Patients from primary care represent a wide range of COPD severity and may have several coexisting diseases, which is also reflected in multifaceted therapies. The ICE COLD ERIC study cohorts will have an important contribution to (prognostic) research on COPD and characterizing COPD patients. The latter may be clinically important not only for its prognostic value but also for its therapeutic value, for a better understanding of the pathophysiology of COPD, and for genetic research in COPD. For example, responses to therapies such as the use of long-term oxygen or lung volume reduction surgery may differ between different (sub)types of patients. ${ }^{25-28}$

The rich variability within the ICE COLD ERIC cohorts offers many opportunities to learn more about the clinical course of COPD in a primary care population that represents the vast majority of COPD patients. The main purpose of the study is development and validation of practical prognostic COPD risk indices. Important risk predictors will be identified for dimensions of health-related quality of life, exacerbation risk, and mortality. For example, health-related quality of life was measured by the CRQ, which provides scores for four different domains. According to the score per domain, physicians may select treatment options for individual patients to improve their (domain-specific) health-related quality of life. Treatment decisions should be based on the needs of the individual patient, probably resulting in fewer unnecessary treatment prescriptions (for example, the widely prescribed inhaled corticosteroids in patients with mild disease), fewer exacerbations, and a better COPD-specific health-related quality of life. COPD management may also become more cost-effective by tailoring treatment decisions better to the needs of the individual patient. 
In a second step, evidence-based treatment effects mainly from randomized trials and meta-analyses will be incorporated, such that the instrument may guide physicians in selecting treatment based on the individual patients' prognoses. Ways to incorporate treatment advices into the prediction indices may be challenging and are currently being explored by this team. For example, a mortality risk of $30 \%$ for a COPD patient may be reduced to $24 \%$ by a certain treatment if the relative risk reduction is 0.8 . The absolute risk reduction is $6 \%$. For another COPD patient with a mortality risk of $3 \%$, that same treatment with a relative risk reduction of 0.8 will reduce the mortality risk to $2.4 \%$, an absolute risk reduction of $0.6 \%$. Adding cost considerations may lead to a recommendation to treat the former and not the latter patient. This is an example of risk-stratified treatment choices.

In summary, COPD patients in ICE COLD ERIC represent a wide range of disease severity and the prevalence of multimorbidity is high. These data show that the impact of COPD can be substantially different across patients even if lung function and the prevalence of comorbidities are quite similar. The rich variation in these prospective cohorts offers good opportunities to learn more about the clinical course of COPD in a primary care population representing the vast majority of COPD patients.

\section{Acknowledgments}

Special thanks go to Ursula Schafroth (Horten Center for Patient-oriented Research, University of Zurich, Zurich, Switzerland) and Alice Karsten and Albertien Buijs (Academic Medical Center, Department of General Practice, University of Amsterdam, Amsterdam, The Netherlands) for their logistical assistance and to the health care centers in Amsterdam and Almere, the participating GPs and COPD patients in Switzerland and The Netherlands who made this study possible by their enthusiastic participation. We thank Professor Elisabeth Bel and Professor Peter Sterk (Department of Respiratory Medicine, Academic Medical Center, University of Amsterdam, Amsterdam, The Netherlands), Professor Erich Russi (Division of Respiratory Medicine, University Hospital of Zurich, Zurich, Switzerland), Professor Roger Goldstein (West Park Health Care Center, University of Toronto, Toronto, Canada), and Professor Jean Bourbeau (Montreal Chest Institute, McGill University, Montreal, Canada) for their advice in the study design. We thank Miranda Roskam-Mul (Department of Clinical Epidemiology, Biostatistics and Bioinformatics, Academic Medical Center, University of Amsterdam, Amsterdam, The Netherlands) for designing the database and Jannik Büscher, Marlou van Rhijn, and Karin Spong for data entry. Finally, we thank Ritesh Ramkhelawan (Faculty of Medicine, University of Amsterdam, Amsterdam, The Netherlands) for his cooperation in performing baseline assessments.

Funding was received from Swiss National Science Foundation (grant \#3233B0/115216/1), Dutch Asthma Foundation (grant \#3.4.07.045), and Zurich Lung League (unrestricted grant).

\section{Disclosures}

The author reports no conflicts of interest in this work. LS, GR, and MP drafted and revised the manuscript. All authors read and corrected draft versions of the manuscript and approved the final manuscript.

\section{References}

1. Puhan MA, Garcia-Aymerich J, Frey M, et al. Expansion of the prognostic assessment of patients with chronic obstructive pulmonary disease: the updated BODE index and the ADO index. Lancet. 2009; 374(9691):704-711.

2. Hurst JR, Vestbo J, Anzueto A, et al. Susceptibility to exacerbation in chronic obstructive pulmonary disease. N Engl J Med. 2010;363(12): 1128-1138.

3. Celli BR, Cote CG, Marin JM, et al. The body-mass index, airflow obstruction, dyspnea, and exercise capacity index in chronic obstructive pulmonary disease. N Engl J Med. 2004;350(10):1005-1012.

4. Celli BR, Calverley PM, Rennard SI, et al. Proposal for a multidimensional staging system for chronic obstructive pulmonary disease. Respir Med. 2005;99(12):1546-1554.

5. Donaldson GC, Wilkinson TM, Hurst JR, Perera WR, Wedzicha JA. Exacerbations and time spent outdoors in chronic obstructive pulmonary disease. Am J Respir Crit Care Med. 2005;171(5): 446-452.

6. Osman IM, Godden DJ, Friend JA, Legge JS, Douglas JG. Quality of life and hospital re-admission in patients with chronic obstructive pulmonary disease. Thorax. 1997;52(1):67-71.

7. Han MK, Agusti A, Calverley PM, et al. Chronic obstructive pulmonary disease phenotypes: the future of COPD. Am J Respir Crit Care Med. 2010;182(5):598-604.

8. Jones RC, Donaldson GC, Chavannes NH, et al. Derivation and validation of a composite index of severity in chronic obstructive pulmonary disease: the DOSE Index. Am J Respir Crit Care Med. 2009; 180(12):1189-1195.

9. Puhan MA, Zoller M, ter Riet G. COPD: more than respiratory. Lancet. 2008;371(9606):27-28.

10. Siebeling L, ter Riet G, van der Wal WM, et al. ICE COLD ERICInternational collaborative effort on chronic obstructive lung disease: exacerbation risk index cohorts - study protocol for an international COPD cohort study. BMC Pulm Med. 2009;9:15.

11. Bestall JC, Paul EA, Garrod R, Garnham R, Jones PW, Wedzicha JA. Usefulness of the Medical Research Council (MRC) dyspnoea scale as a measure of disability in patients with chronic obstructive pulmonary disease. Thorax. 1999;54(7):581-586.

12. Puhan MA, Behnke M, Laschke M, et al. Self-administration and standardisation of the chronic respiratory questionnaire: a randomised trial in three German-speaking countries. Respir Med. 2004;98(4): 342-350.

13. Puhan MA, Behnke M, Frey M, et al. Self-administration and interviewer-administration of the German Chronic Respiratory Questionnaire: instrument development and assessment of validity and reliability in two randomised studies. Health Qual Life Outcomes. 2004;2:1. 
14. Schunemann HJ, Puhan M, Goldstein R, Jaeschke R, Guyatt GH. Measurement properties and interpretability of the Chronic Respiratory disease Questionnaire (CRQ). COPD. 2005;2(1):81-89.

15. Puhan MA, Behnke M, Devereaux PJ, et al. Measurement of agreement on health-related quality of life changes in response to respiratory rehabilitation by patients and physicians - a prospective study. Respir Med. 2004;98(12):1195-1202.

16. Puhan MA, Guyatt GH, Montori VM, et al. The standard gamble demonstrated lower reliability than the feeling thermometer. $J$ Clin Epidemiol. 2005;58(5):458-465.

17. Torrance GW, Feeny D, Furlong W. Visual analog scales: do they have a role in the measurement of preferences for health states? Med Decis Making. 2001;21(4):329-334.

18. Puhan MA, Frey M, Buchi S, Schunemann HJ. The minimal important difference of the hospital anxiety and depression scale in patients with chronic obstructive pulmonary disease. Health Qual Life Outcomes. 2008;6:46

19. Snaith RP. The hospital anxiety and depression scale. Health Qual Life Outcomes. 2003;1:29.

20. Ozalevli S, Ozden A, Itil O, Akkoclu A. Comparison of the Sit-to-Stand Test with 6 min walk test in patients with chronic obstructive pulmonary disease. Respir Med. 2007;101(2):286-293.

21. Bohannon RW, Peolsson A, Massy-Westropp N, Desrosiers J, Bear-Lehman J. Reference values for adult grip strength measured with a Jamar dynamometer: a descriptive meta-analysis. Physiotherapy. 2006; 92(1):11-15.
22. Agusti A, Calverley PM, Celli B, et al. Characterisation of COPD heterogeneity in the ECLIPSE cohort. Respir Res. 2010;11:122.

23. Wedzicha JA, Calverley PM, Seemungal TA, Hagan G, Ansari Z, Stockley RA. The prevention of chronic obstructive pulmonary disease exacerbations by salmeterol/fluticasone propionate or tiotropium bromide. Am J Respir Crit Care Med. 2008;177(1):19-26.

24. Chavannes N, Stallberg B, Lisspers K, et al. UNLOCK: Uncovering and Noting Long-term Outcomes in COPD to enhance knowledge. Prim Care Respir J. 2010;19(4):408.

25. Friedlander AL, Lynch D, Dyar LA, Bowler RP. Phenotypes of chronic obstructive pulmonary disease. COPD. 2007;4(4):355-384.

26. Continuous or nocturnal oxygen therapy in hypoxemic chronic obstructive lung disease: a clinical trial. Nocturnal Oxygen Therapy Trial Group. Ann Intern Med. 1980;93(3):391-398.

27. Long term domiciliary oxygen therapy in chronic hypoxic cor pulmonale complicating chronic bronchitis and emphysema. Report of the Medical Research Council Working Party. Lancet. 1981;1(8222):681-686.

28. Fishman A, Martinez F, Naunheim K, et al. A randomized trial comparing lung-volume-reduction surgery with medical therapy for severe emphysema. N Engl J Med. 2003;348(21):2059-2073.
Clinical Epidemiology

\section{Publish your work in this journal}

Clinical Epidemiology is an international, peer-reviewed, open access journal focusing on disease and drug epidemiology, identification of risk factors and screening procedures to develop optimal preventative initiatives and programs. Specific topics include: diagnosis, prognosis, treatment, screening, prevention, risk factor modification, systematic

\section{Dovepress}

reviews, risk \& safety of medical interventions, epidemiology \& biostatical methods, evaluation of guidelines, translational medicine, health policies \& economic evaluations. The manuscript management system is completely online and includes a very quick and fair peer-review system, which is all easy to use. 